\title{
PERCEPCIONES DEL SISTEMA JUDICIAL SOBRE EL DERECHO AL ESPACIO PÚBLICO: EL CASO DE LA VENTA CALLEJERA EN LA CIUDAD DE BUENOS AIRES, ARGENTINA
}

\section{PERCEPTIONS OF THE JUDICIAL SYSTEM ON THE RIGHT TO PUBLIC SPACE: THE CASE OF STREET VENDING IN BUENOS AIRES, ARGENTINA}

\section{Anahí Patricia Gonzalez ${ }^{1}$}

\begin{abstract}
En todas las leyendas y cantos de esa ciudad, está el anhelado vaticinio de un día en el que cinco golpes sucesivos de un puño gigantesco aniquilarán la ciudad. Por esa causa existe un puño en el escudo de armas.

(Kafka, F., 2003:372)
\end{abstract}

\section{Resumen}

A partir del análisis del caso de la venta callejera por parte de migrantes en la Ciudad Autónoma de Buenos Aires (CABA), en Argentina, el artículo aborda la cuestión de los modos en que el sistema judicial de dicha jurisdicción gestiona el espacio público sancionando, controlando y estigmatizando ciertas prácticas comerciales, mayormente de subsistencia. Con este objetivo, se analizan cincuenta entrevistas realizadas a miembros del sistema judicial de la CABA efectuadas durante los años 2011-2014, en el marco de un proyecto de investigación UBACYT con sede en el Instituto de Investigaciones Gino Germani de la Facultad de Ciencias Sociales de la Universidad de Buenos Aires. De los discursos de los entrevistados, se han analizado aquellas dimensiones que referían a la administración de la justicia y la problemática de la venta callejera desempeñada por migrantes fundamentalmente de origen paraguayo, boliviano, peruano y senegalés, procurando conocer cuáles son las representaciones sociales existentes al respecto en el sistema judicial.

Palabras claves: Migraciones- Espacio Público-Sistema Judicial

\begin{abstract}
Starting from the study of the street-sales case by migrants in the City of Buenos Aires (CABA) in Argentine, this article analyzes the question of the ways in which the judicial system, in this jurisdiction, manages the public space, punishing, controlling and stigmatizing certain practices commercial, mostly subsistence. For that purpose, fifty interviews of members of the judiciary of the CABA, made during the years 2011-2014 are analyzed, under a Research Project UBACYT, at the Gino Germani Research Institute of the Faculty of Social Sciences in the Buenos Aires University. Of interviewee's discourses, were analyzed those dimensions related to the administration of justice and the problem of street vending by International migrants, mainly mainly Paraguayans, Bolivians, Peruvians and Senegalese, seeking to know what the social representations on the matter are in the judicial system.
\end{abstract}

Keywords: Public- migrations- Space Judicial System

\footnotetext{
${ }^{1}$ Doctora en Ciencias Sociales. Docente de la Facultad de Ciencias Sociales, Universidad de Buenos Aires UBA. Becaria post doctoral CONICET con sede en el Instituto de Investigaciones Gino Germani, Facultad de Ciencias Sociales, Universidad de Buenos Aires - UBA. Email: anahipgonzalez@gmail.com
} 


\section{INTRODUCCIÓN}

El presente artículo aborda la cuestión de los usos del espacio público y el acceso a determinados derechos que aquellos usos implican. Particularmente, analiza las representaciones sociales $^{2}$ de los miembros del sistema judicial acerca de los migrantes internacionales que comercian en la vía pública de la Ciudad de Buenos Aires. En este sentido, la venta callejera supone una serie de conflictos que refieren al ordenamiento legal y moral del espacio. En las páginas que siguen se analizan las normas, percepciones y prácticas que el sistema judicial de la Ciudad Autónoma de Buenos Aires (CABA) re-produce cotidianamente en su tarea de administrar la ley en relación al ordenamiento y gestión del espacio público³.

Teniendo en cuenta lo planteado hasta aquí el artículo se estructura del siguiente modo.

En primer lugar, se presentan algunos datos sobre las migraciones internacionales en Argentina a modo de contextualización. Seguidamente, se precisan cuestiones teóricas sobre el tema del espacio público. En tercer lugar, se realizan algunas aclaraciones respecto al Código Contravencional de la Ciudad de Buenos Aires, explicitándose los artículos que regulan la actividad de venta callejera en el Código. Asimismo, se explica cuáles son las competencias y tareas del poder judicial a nivel de la Ciudad en relación a la infracción en cuestión.

Luego, se analizan los resultados de las entrevistas realizadas a los miembros del sistema judicial considerando dos aspectos: las "dimensiones legales" y las "dimensiones morales" que, desde las percepciones de los entrevistados, se verían afectadas por las prácticas de los extranjeros. En estos apartados se sostiene el supuesto de que la "solución represiva" impide visibilizar la puja por derechos que en realidad se esconde detrás del conflicto contravencional.

Finalmente, se presentan las reflexiones finales.

\footnotetext{
2 Se parte de la definición de Jodelet $(1986,1991)$ quien enmarca la existencia de las representaciones en la necesidad que tenemos todos los sujetos de saber a qué atenernos ante el mundo que nos rodea, así: ..." ante un mundo de objetos, personas, sucesos e ideas no estamos equipados únicamente de automatismos, ni estamos aislados en un medio social, sino que lo compartimos con otros, nos apoyamos en ellos- a veces en el acuerdo, a veces conflictivamente- para comprenderlo, controlarlo o afrontarlo. (...) Ellas nos orientan en la manera de designar y definir conjuntamente los diferentes aspectos de nuestra realidad diaria, en la manera de interpretarlos, influir sobre ellos y, en caso contrario, tomar una posición ante ellos y defenderla". (Jodelet, 1986:67)

${ }^{3}$ Los resultados aquí presentados forman parte de una investigación de mayor envergadura: Proyecto UBACYT: "Diversidad etno-nacional y construcción de desigualdades en las instituciones escolar y judicial. Un desafío teórico-metodológico en el abordaje de los casos del AMBA y la provincia de Mendoza correspondiente a la Programación Científica 2011-2014 y con sede en el Instituto de Investigaciones Gino Germani (IIGG/FCS/UBA)con sede en el Instituto de Investigaciones Gino Germani (IIGG/FCS/UBA)
} 


\section{CONTEXTUALIZANDO EL FENÓMENO DE LAS MIGRACIONES EN ARGENTINA Y EL ROL DEL ESTADO}

Argentina ha sido un país cuya historia se ha visto atravesada por la llegada de migrantes. Las olas masivas de migraciones se dieron, fundamentalmente, a fines del siglo XIX y mediados del siglo XX. Se trató fundamentalmente de extranjeros que provenían de Italia y España. Paulatinamente, esta migración transoceánica irá siendo numéricamente menor. Al mismo tiempo, los migrantes regionales ${ }^{4}$ - si bien ya llegaban durante la época del arribo intensivo de las migraciones provenientes de Europa- comienzan a crecer en número como también la visibilización de su presencia por parte de la sociedad receptora.

Desde los comienzos del Estado Argentino la gestión de las migraciones fueron parte de una política de Estado. Así, los artículos 20 y 25 de la Constitución Nacional de 1853 serán las primeras medidas relevantes a nivel normativo que el estado argentino toma, respecto a las migraciones.

Los extranjeros gozan en el territorio de la Nación de todos los derechos civiles del ciudadano; pueden ejercer su industria, comercio y profesión; poseer bienes raíces, comprarlos y enajenarlos; navegar los ríos y costas; ejercer libremente su culto; testar y casarse conforme a las leyes. No están obligados a admitir la ciudadanía ni a pagar contribuciones forzosas extraordinarias. Obtienen nacionalización residiendo dos años continuos en la Nación; pero la autoridad puede acortar este término a favor del que lo solicite, alegando y probando servicios a la República. (Art. 20)

El Gobierno federal fomentará la inmigración europea; y no podrá restringir, limitar ni gravar con impuesto alguno la entrada en territorio argentino de los extranjeros que traigan por objeto labrar la tierra, mejorar la industrias, e introducir y enseñar las ciencias y las artes. (Art. 25)

Como se evidencia en la lectura de estos artículos, el tipo de migraciones a alentar y su gestión se vinculaban directamente con el modelo de país que, tanto a nivel económico como político, se pretendía instaurar. Con un marcado tinte instrumental, que impulsara la modernización del país, los "...hombres de todo el mundo que quieran habitar en el suelo

\footnotetext{
${ }^{4}$ Escapa a los objetivos del presente artículo la cuestión de la invisibilización que las migraciones regionales, presentes desde los comienzos de la conformación del estado nacional argentino, han tenido en las diversas interpretaciones historiográficas, no obstante, dichas migraciones formaban parte de la realidad social en una época en que las fronteras geográficas estaban aun definiéndose. Para un análisis sobre este tema puede consultarse: Benencia, R. (2003). Apéndice. La inmigración limítrofe. En Devoto, F. Historia de la inmigración de la Argentina (págs. 433-484). Buenos Aires: Sudamericana.
} 
argentino..." serían aquellos provenientes de Europa, más precisamente, ingleses, alemanes, franceses y suizos que colonizaran el campo y aportaran su fuerza de trabajo para el desarrollo productivo. En esa construcción imaginaria del progreso, la inmigración ocupaba un rol central. Europa era sinónimo de civilización. El espíritu de esas ideas, que pueden verse plasmado en parte en la Constitución del 53’ y luego en la ley 817 o Ley Avellaneda, se mantendrá en las diversas normativas dictaminadas posteriormente.

Frente a esta política, orientada a ese tipo de "migrante ideal", los que efectivamente llegarían provendrían de las regiones pobres de Italia y España. Muchos de ellos trayendo consigo las experiencias del movimiento obrero. Las leyes de Residencia (1902) y de Defensa Social (1910) apuntarán a criminalizar a sectores socialistas y anarquistas. Ambas leyes establecieron como pena la expulsión de aquellos extranjeros que fueran considerados "peligrosos" para el orden social. Luego de estas leyes, se sucederán una serie de decretos emanados por el Poder Ejecutivo pero ninguna ley más sobre cuestiones migratorias se sancionará hasta 1981 cuando se promulgue la conocida como "Ley Videla", la misma suponía "... la restricción en el goce de derechos fundamentales (civiles, económicos y sociales) para quienes se encuentren en situación irregular." Courtis (2006:192). Finalmente, esta ley será reemplazada por la vigente hoy día, Ley 25871, y que significó un avance sustancial en cuanto al reconocimiento formal de los derechos de los migrantes internacionales y estableciendo a la migración como un derecho humano 5 .

Actualmente, según datos del último Censo Nacional de Población, Hogares y Viviendas (2010) la población migrante que habita en Argentina constituye un 4,5 \% de la población total. En números absolutos 1.805.957. El 81, 2\% son extranjeros procedentes de América, seguidamente el 16,5\%, de Europa; en tercer lugar de Asia $(1,7 \%)$, seguido por África $(0,2 \%)$, y por último, de Oceanía (0,1 \%). Asimismo, la Ciudad Autónoma de Buenos Aires es la jurisdicción con mayor proporción de población nacida en el extranjero, pues presenta un 13,2\% sobre la población total. Acerca de esta Ciudad es sobre la que versarán los testimonios de los entrevistados analizados en el presente artículo.

\footnotetext{
${ }^{5}$ Excede a los propósitos del presente escrito realizar un análisis sobre la totalidad de normativas sobre migraciones que Argentina tiene y ha tenido. Al respecto, resultan recomendables lo siguientes trabajos: CERIANI CERNADAS, P., \& FAVA, R. (2009). Políticas migratorias y derechos humanos. Buenos Aires: Ediciones de la UNLa.; Courtis, C. (2006). Hacia la derogación de la Ley Videla: la migracion como tema de labor parlamentaria en la Argentina de la década de 1990. En JELIN, \& GRIMSON, Migraciones regionales hacia la Argentina: diferencia, desigualdad y derechos. Buenos Aires: Prometeo. ;MÁRMORA, L. (2004). Las leyes de migraciones como contexto normativo. (De la ley Videla a la Ley de Migraciones 25.871). En GIUSTINIANI, R. Migración: un derecho humano (págs. 59-66). Buenos Aires: Prometeo. ;MORALES, D. (Septiembre de 2012). Derechos Humanos de los migrantes en la Argentina. Apuntes sobre nuevas perspectivas jurisprudenciales. (D. T. Legal, Ed.) Revista de Derecho Público, 1(2).; NOVICK, S. (2012). Migración y políticas en Argentina: Tres leyes para un país extenso. Revista Voces en el Fenix(21), 1-35.
} 


\section{SOBRE EL ESPACIO PÚBLICO EN LA CIUDAD AUTÓNOMA DE BUENOS AIRES}

El derecho al espacio público refiere al derecho a ser incluido en la vida de la ciudad, en el espacio urbano. Las modalidades en las que ese espacio es apropiado por los diversos sectores que viven o transitan en el mismo permiten identificar el modo como son visibilizados/invisibilizados cada uno de los grupos sociales. Asimismo, en el caso de sectores vulnerables permite evidenciar en qué grado son reconocidos y distribuidos los derechos de los mismos y quiénes son considerados como los usuarios legítimos del espacio y sus bienes. En otros términos, las desigualdades sociales se cristalizan en el espacio. Allí, se reproducen las desigualdades sociales que pueden encontrarse también en el acceso a determinadas instituciones educativas, servicios de salud, acceso a vivienda, a la justicia, etc. En palabras de Carrión Mena (2004:61) el espacio público es "un ámbito contenedor de la conflictividad social, que tiene distintas posiciones dependiendo de la coyuntura y de la ciudad que se trate".

Fundamentalmente, el derecho al espacio público, refiere a un espacio urbano, es decir, a la ciudad, la cual es entendida como una fuente de recursos (económicos, sociales, culturales) cuya distribución resulta desigual y vinculada a la localización espacial. En palabras de Bourdieu (1993:120):

El espacio social reificado se presenta como la distribución en el espacio físico de diferentes especies de bienes y servicios y también de agentes individuales y grupos localizados físicamente (en tanto cuerpos vinculados a un lugar permanente) y provistos de oportunidades más o menos importantes de apropiación de esos bienes y servicios (en función de su capital y también de la distancia física con respecto a esos bienes, que depende igualmente de aquél.) En la relación de la distribución de los agentes y la distribución de los bienes en el espacio se define el valor de las diferentes regiones del espacio social reificado.

En consecuencia, el modo en que se configura el espacio público entrevé cómo se estructuran, construyen y deconstruyen las relaciones de dominación. Apropiarse del espacio, supone establecer una relación de poder con otros permitiendo identificar quiénes se encuentran en una posición de vulnerabilidad, quiénes de privilegio y qué resistencias e intentos de sobrevivencia son desplegadas por los miembros de una sociedad.

En este sentido, diversas investigaciones señalan que los migrantes regionales, principalmente los paraguayos, bolivianos y peruanos no habitan las zonas más favorecidas de la ciudad. (Marcos y Mera, 2009) Lo que se traduce en una calidad inferior en el acceso a determinados servicios tales como el acceso a la vivienda, a empleos, salud y educación, etc. 
En el caso del acceso a empleos, los migrantes se hacen visibles y "molestos" cuando, ya sea trasladándose o nó desde sus lugares de residencia, hacen uso del espacio público desarrollando actividades comerciales. Dicha actividad es visibilizada además de modo negativo por gran parte de la sociedad, irónicamente y a pesar que muchos sean clientes. Asociada al contrabando, la evasión impositiva, el trabajo informal, la competencia comercial "desleal", etc; en fin, a una serie de ilegalidades e ilegalismos personificados en quienes se dedican a esas tareas, presentándose aun más graves si se trata de extranjeros.

Por otra parte, resulta preciso explicitar que, en el análisis realizado en el artículo subyace como una idea central que el espacio público es actualmente un lugar de especial atención para ciertas políticas contra la criminalidad. Estas perspectivas obsesionada por el control, la gestión de determinados grupos, la redistribución del riesgo, la constitución de "clases peligrosas" se caracterizan por la edificación de fronteras, por intervenir en los comportamientos y en el ambiente no ya, solamente, intramuros de instituciones totales, como la cárcel o los reformatorios, sino también de modo más difuso, vigilando sobre todo a los grupos económicamente más vulnerables y focalizándose en la prevención de la criminalidad callejera y del espacio urbano. (De Giorgi, 2005). Sobre esta cuestión se volverá más adelante, solo resulta importante señalar aquí que, en este contexto, son ciertos colectivos y delitos los que fundamentalmente serán perseguidos, así como determinados grupos los identificados y señalados como potenciales infractores. En términos de Wacquant, 2009:33)

Estas categorías de parias- jóvenes desempleados librados a su suerte, mendigos y sin techo nómadas sin rumbo y drogadictos e inmigrantes (...) sin documentos ni apoyo- se han hecho notar en el espacio público, su presencia se ha vuelto indeseable y sus actos intolerables porque son la encarnación viviente y amenazadora de la inseguridad social generalizada producida por la erosión del trabajo estable y homogéneo (promovido al rango de paradigma del empleo durante las décadas de la expansión fordista en 1945-1975), y por la descomposición de las solidaridades de clase y de cultura que la sostenían en un marco nacional claramente circunscripto.

En suma, el aspecto represivo y de control se orienta hacia ciertos grupos, como los extranjeros, que intentan suplir necesidades insatisfechas a partir de prácticas consideradas desviadas y/o ilegales en el espacio público.

\section{LA NOCIÓN DE ESPACIO PÚBLICO EN EL CÓDIGO CONTRAVENCIONAL DE LA CIUDAD AUTÓNOMA DE BUENOS AIRES}


La novedad de la época moderna, “... consistió en postular la transparencia y la legibilidad como un objetivo que se ha de buscar de manera sistemática." (Bauman, 1999:46) Solamente así el Estado podría garantizar la administración y planificación de los asuntos económicos y políticos de la ciudad. Organizar el espacio público implicó separar espacialmente las partes dedicadas a las diferentes funciones sociales y a la calidad de sus habitantes. Se trataba de hacer de la ciudad un espacio perfectamente transparente, reducir la opacidad, lograr una racionalidad feliz donde reinara la belleza estética y la lógica funcional. (Bauman, 1999)

Domesticar el espacio supone volver al territorio inteligible y conocido. Las leyes resultan ser unas excelentes aliadas para ello ya que suponen el establecimiento de límites claros e inapelables. La organización espacial de la Ciudad de Buenos Aires ha seguido la lógica que Bauman (1999) atribuyera a la modernidad. De hecho, dicho autor, menciona a Buenos Aires, junto con Río de Janeiro y Paris, como los ejemplos sobre los que se basó el libro, publicado en la década de 1930, "La ciudad radiante" de Le Corbusier, que resultase ser el evangelio del modernismo urbano. Así los tres proyectos urbanísticos “...parten de cero y obedecen únicamente las normas de la armonía estética y la lógica impersonal de la división funcional." A partir de la delimitación de zonas, lugares y comportamientos "apropiados para la gente decente" se establecieron ámbitos privados y públicos.

El espacio abierto de plazas, calles, mercados, mataderos, puertos y ríos fue estudiado y diseñado a fin de poder observar, controlar y normalizar los movimientos de bienes y personas. El espacio de la casa que tradicionalmente se abría al barrio, fue tornándose paulatinamente cerrado, interior, aunque su fachada y su recibidor mostraron la cara que las familias de clases medias en ascenso deseaban exhibir hacia el mundo. (Murillo, 2002: 43).

Los edictos policiales- que otorgaban a la policía la facultad de detener y juzgar personasactuaron primeramente como dispositivo de control de los sujetos señalados como desviados de la norma en la Ciudad de Buenos Aires. Posteriormente, Buenos Aires continuó regulando los usos de la Ciudad $^{6}$ incorporando el aspecto legislativo. Se sanciona en 1998 el Código de Convivencia Urbana para la Ciudad de Buenos Aires el cual tendría una serie de modificaciones con el correr del tiempo. Finalmente, en el año 2004, se deroga el Código de Convivencia Urbana (Ley 10) y, en su reemplazo, se sanciona el Código Contravencional de la Ciudad (Ley 1472). Este código, en

\footnotetext{
6 Sobre este tema puede verse el trabajo de Tiscornia, Sarrabayrouse Oliveira y Eilbaum (2004) De los edictos de policía al Código de Convivencia Urbana. Las trágicas paradojas de los procesos de construcción de espacios de convivencia". En Tiscornia,S. (comp.) Burocracias y violencia. Estudio de antropología jurídica. Buenos Aires: Antropofagia, 2004.

7 Sobre un análisis más profundo sobre el Código Contravencional puede consultarse http://www.aacademica.com/000-038/565.pdf
} 
vigencia actualmente, establece cuáles son las penas, los rangos de las mismas así como incorpora nuevas conductas bajo la figura contravencional. En el 2011 se introducen algunos cambios, entre ellos, se modifica el artículo 83 referido al uso indebido del espacio público, eliminando a la consideración de las actividades de venta callejera que se realizaran para la "mera subsistencia" como motivo de eximición de pena. Ahora sólo estaría permitida la venta ambulatoria “...siempre que no implicara una competencia desleal con los comercios establecidos". De esta manera, el artículo 83 especifica:

Usar indebidamente el espacio público. Quien realiza actividades lucrativas no autorizadas en el espacio público, es sancionado/a con multa de doscientos $(\$ 200)$ a seiscientos $(\$$ $600)$ pesos. Quien organiza actividades lucrativas no autorizadas en el espacio público, en volúmenes y modalidades similares a las del comercio establecido, es sancionado/a con multa de 5.000 a 30.000 pesos. No constituye contravención la venta ambulatoria en la vía pública o en transportes públicos de baratijas o artículos similares, artesanías y, en general, la venta de mera subsistencia que no impliquen una competencia desleal efectiva para con el comercio establecido, ni la actividad de los artistas callejeros en la medida que no exijan contraprestación pecuniaria.

Se establece además en el artículo 84 la pena correspondiente:

Ocupar la vía pública. Quien ocupa la vía pública en ejercicio de una actividad lucrativa excediendo las medidas autorizadas o el permiso de uso de las aceras, es sancionado/a con multa de cuatrocientos (\$400) a dos mil (\$2.000) pesos.

Los artículos del Código Contravencional, como los citados anteriormente, establecen cuáles son las actividades que pueden desarrollarse y cuáles no, asentándose en la fuerza de la ley, inherente al Código. La inadvertencia, subyacente a la violencia simbólica ${ }^{8}$ ejercida en la determinación por parte del sistema judicial de las conductas desviadas, se fundamenta entonces en la norma. En este sentido, no hay lugar para la duda o el cuestionamiento ya que es lo que la ley manda.

Bueno, hay por todos lados. Eso es una contravención, para la ley contravencional y demás. Están laburando, pero la ley no los acompaña." (Escribiente, 2 años en el sistema judicial.)

\footnotetext{
${ }^{8}$ Se entenderá la violencia simbólica como aquella "...violencia amortiguada, insensible, e invisible para sus propias víctimas, que se ejerce esencialmente a través de los caminos puramente simbólicos de la comunicación y del conocimiento o, más exactamente, del desconocimiento, del reconocimiento (...) Esta relación social extraordinariamente común ofrece una ocasión privilegiada de entender la lógica de la dominación ejercida en nombre de un principio simbólico conocido y admitido tanto por el dominador como por el dominado, un idioma (o una manera de modularlo), un estilo de vida (o una manera de pensar, de hablar o de comportarse) y, más habitualmente, una característica distintiva, emblema o estigma..." (Bourdieu, 2000:12). Asimismo, hablar de violencia simbólica, supone recordar que lo simbólico no es opuesto a lo real, no se trata de una violencia espiritual, sin efectos reales.
} 
Ahora bien, en este sentido es que, como sostiene Becker (2009: 28), "la desviación es creada por la sociedad":

"Los grupos sociales crean la desviación al establecer las normas cuya infracción constituye una desviación y al aplicar esas normas a personas en particular y etiquetarlas como marginales. Desde este punto de vista, la desviación no es una cualidad del acto que la persona comete, sino una consecuencia de la aplicación de reglas y sanciones sobre el "infractor" a manos de terceros. Es desviado quien ha sido exitosamente etiquetado como tal, y el comportamiento desviado es el comportamiento que la gente etiqueta como tal.

De esta manera, para que un vendedor callejero sea considerado un desviado debe haber existido un proceso en el que determinados sectores producen esa ley cuya norma resultante especifique que la conducta en cuestión es contraria a, en este caso, el uso debido del espacio público. Pero además, los sujetos que cometan la infracción deben ser señalados y sancionados como infractores, es por ello que Becker (2009) dice que el desviado es aquel que ha sido exitosamente etiquetado como tal.

Otro aspecto a considerar en la administración del control del espacio público de la CABA es que, con la ley 26.7029 promulgada en 2011, se transfieren una serie de delitos del ámbito de la justicia nacional a la Ciudad de Buenos Aires, determinando nuevas obligaciones en la administración de las conductas desviadas, así como, definiendo las penas a aplicar.

"En el Fuero Contravencional, originalmente, sólo trabajaban con los viejos edictos policiales, que luego de la reforma se crea el Código Contravencional, que va a tener sus discusiones también, pero mucho menos que los viejos edictos policiales. Es como si fuera una ley penal pero menos agresiva para el imputado. Menos agresivo porque las conductas son conductas cotidianas: la venta ambulante, la oferta y demanda de sexo en la vía pública, los ruidos molestos, el ingreso a lugares de espectáculos públicos, son todas... tenencia de arma... portación de armas no convencional, que ahí puede entrar media tijera o una réplica, o sea una pistola de juguete, o un tramontina. Hay muchos casos de gente que vive en situación de calle, no sé si es un término correcto, que tiene su cuchillo, tiene su tenedor, tiene su cuchara y su olla; el cuchillo, si se complica con la policía, pasa a ser un arma no convencional y pasa a tener una contravención. Contravención rara vez termina en privación de libertad. Solamente se estipula algunos días y según el tipo contravencional, generalmente es una multa, y generalmente son probation. Porque muchas veces, como la población es pobre, no hay plata para multas. (...) El juez contravencional

\footnotetext{
${ }^{9}$ Disponible en: http://www.infoleg.gov.ar/infolegInternet/anexos/185000-189999/187845/norma.htm
} 
antes de tener los delitos era sólo juez contravencional. Entonces era un juez. chiquitaje. (Escribiente, 3 años en el sistema judicial.)

De esta manera, inicialmente con los edictos policiales (criticados por el nivel de discrecionalidad que implicaban ya que colocaba el poder total de control en manos de la policía) luego eliminados por el Código de Convivencia Urbana con sus sucesivas modificaciones y el desarrollo de la justicia contravencional, se iría desplegando un sistema de control del espacio en que el entramado de funciones se complementaban, superponían y en ocasiones podían contradecirse. Asimismo, como plantean Tiscornia, et. al (2004:91)

Parece sugerente pensar que la nueva justicia contravencional y su ejercicio ocupa, al mismo tiempo que produce, nuevos espacios. Por un lado, un espacio real-institucional constituido por nuevos/viejos edificios, oficinas, funcionarios, clientes; por el otro, un espacio social, conformado por nuevas/tradicionales relaciones de poder, por discursos de funcionarios, expertos, mediáticos, de la calle y del sentido común; por disputas por los límites de la definición de la público y lo privado.

Las diversas funciones penalizadoras, a partir de la determinación de las nuevas competencias de la justicia de la Ciudad de Buenos Aires ${ }^{10}$ sumadas a lo estipulado en el Código Contravencional, se proyectan, en parte, en la organización socio espacial de la Ciudad, entendida como la acción de definir cuáles son los usos y modos de apropiación del espacio que están por fuera y por dentro de la norma. En suma, al definir las conductas que serán catalogadas como desviadas.

Específicamente, aquellas actividades consideradas faltas o contravenciones son indicadas por los miembros del sistema judicial de la CABA como conductas que "no son graves", que "no pueden considerarse delitos" o en palabras del entrevistado citado anteriormente: "Es como si fuera una ley penal pero menos agresiva para el imputado. Menos agresivo porque las conductas son conductas cotidianas". Se reitera en las entrevistas el desmerecimiento de este tipo de actividades desviadas consideradas como seudo delitos o como seudo- desviaciones. Sin embargo, no dejan de ser perseguidas y criminalizadas. De este modo, a la cotidianeidad-como dice el entrevistado- de esas acciones le corresponde una proporcional cotidianeidad en su persecución por parte del sistema judicial local. Una de esas conductas desviadas de la norma es la venta callejera.

\footnotetext{
${ }^{10}$ Es a partir de la reforma de 1994 de la Constitución Nacional que se establece la autonomía de la Ciudad de Buenos Aires suponiendo ello que la Ciudad debería tener también un poder judicial propio. Si bien se avanzó hacia ello, al sancionarse la Constitución de la Ciudad de Buenos Aires en 1995, lo cierto fue que las dos leyes que regulan la autonomía de la Ciudad definieron que solo se traspasarían, de la Justicia Nacional a la de la Ciudad, la justicia contencioso-administrativa y la contravencional.
} 
Sea considerada una falta o contravención, en la penalización de la venta callejera, coinciden, diversas instancias, todas con el mismo objetivo: "ordenar" la actividad considerada ilícita. Se trata de un control a nivel micro, ejercido de modo periódico y rutinario que, consecuentemente, se ha vuelto habitual y, en cierta medida, se ha naturalizado.

Los castigos suponen una multa, la confiscación de los medios de vida de los vendedores, en el caso de los extranjeros detenciones en el caso de no contar con documentación que acredite su identidad, etc. De modo que, lo calificado como "errático" por los entrevistados resulta ser un modo de proceder estatal que califica, clasifica y sanciona rutinariamente (ya sea por medio del poder de la policía, de la administración o del poder judicial) prácticas catalogadas por la ley como desviadas.

La falta, las debe labrar la policía, y le debe dar intervención al Gobierno de la Ciudad, el Gobierno de la Ciudad le debe aplicar una multa, y uno ahí tiene el derecho de defensa (...). Poder de policía local, ejercido por la Policía Federal Argentina, con intervención administrativa del Gobierno de la Ciudad. 80 \%, solo una pequeñísima parte, o solo una pequeña parte es la que, de hecho, muchos casos le dan intervención a la Justicia, y la Justicia los termina remitiendo a Faltas. El $30 \%$ de nuestros casos que entran por contravenciones, se remiten a la Unidad Administrativa de Control de Faltas, porque son faltas. Derivación: 22, 7. Este es un tablero de control al día. Este porcentaje de todas las resoluciones que nosotros concluimos, es porque se lo mandamos a Faltas porque consideramos que no hay Contravención. Se archiva el $65 \%$ de los casos porque no hay contravención. La fuerza de seguridad labró un acta que no era una contravención. Entonces, el tema del espacio público, que es un tema donde se dan estas situaciones que hablábamos al principio, de injusticias, de aprovechamientos, de la población más vulnerable, es un espacio, que ante la falta de definiciones de políticas públicas y demás, es un espacio que queda como bajo la esfera de las fuerzas de seguridad. (Fiscal, 22 años en el sistema judicial.)

En suma, el poder estatal de sancionar se presenta como un modo más de ordenar el espacio y a los sujetos que se encuentran en él. Sin duda, sin olvidar lo que la ley establece y que los miembros de las instancias estatales dicen aplicar como parte de sus funciones, existe un suplemento ligado a la discrecionalidad a la que los entrevistados aluden. En ese proceso el sujeto penado- muchos de ellos migrantes, como puede verse en los testimonios- es colocado en una situación de vulnerabilidad por el que atraviesa en los diversos pasos que implican el acto de sancionar. La posibilidad de ser escuchado o considerado como sujeto de derecho se ve afectada por el entramado de prácticas institucionalizadas y burocráticas que se reproducen casi como si no hubiera sujetos involucrados en las mismas. 
Yo he tenido casos en los cuales gente de República Dominicana, gente de Perú. Y gente sí, también de Paraguay cuando vienen y nos piden por ejemplo, la devolución del no sé: de la canasta con la comida que tenía en Constitución y nosotros se la, eso no lo consideramos una contravención. Porque la contravención es más grave que la falta. Cuando vemos que sólo es, cuando ejerce esa actividad usando el espacio público para sólo subsistencia lo consideramos sólo una falta que es menor entonces le explicamos: "no. Tiene que ir a tal lugar porque la causa como entró nosotros, la analizamos y se la mandamos a la unidad de control de faltas". No entiende. Dice: "no, pero quien me secuestró fue la policía por orden de ustedes." Está bien. Entonces tenemos este tipo de consultas en los cuales al entrar lo que es el sistema judicial y al aparato del Estado tenemos esa, como hay, si bien acá desformalizamos mucho y no es tan burocrático, pero tenemos. Lamentablemente al ser del Estado tenemos que burocratizar mínimamente algo. $Y$ burocratizar en el buen sentido de la palabra. Y mandarlo a lo que nosotros decimos, mandarlo a la Unidad de Control de Faltas, la persona tiene un acta en la cual se le dice que se le hizo hacer una contravención: "No pero a mí me hicieron hacer una contravención". "Sí. Pero el fiscal recalificó y consideró que era una falta. (Prosecretario administrativo, 5 años en el sistema judicial.)

El asedio constante que implica para los migrantes, una vez que han sido "tocados" por algunas de las instancias del sistema de control de la Ciudad, tiene como objetivo la regulación de los espacios ocupados para el desarrollo de la actividad de comerciar, dado que la venta de artículos en la vía pública entra en contradicción además con derechos (de propiedad) vinculados al desarrollo de la actividad de modo legal.

La ciudad se presenta, al decir de Oszlak, como un ámbito más del mercado en el que los sujetos pueden apropiarse de recursos económicos. Así, no es sólo un lugar de tránsito, sino que para los sectores más vulnerables de la sociedad puede ser vista como una-sino la única- fuente de recursos materiales, donde ciertos bienes y prácticas desestimadas por el resto de los ciudadanos, toman la forma de mercancías. Como se mencionó anteriormente, en el caso de los migrantes, la sanción que puede suponer la confiscación de los productos comercializados, incluye otra posible la pena: detención. La misma se produce, según los entrevistados, por la imposibilidad de los extranjeros de poder acreditar identidad a falta de contar con el Documento Nacional de Identidad (DNI).

Al llegar al país la comunidad de ellos tiene organizado la venta de bijouterie de fantasía, como carecen de documentos, cuando se le abre una contravención sufre lo único que la contravención tiene como última...ratio que es la pena de arresto, lo sufre...para acreditar su identidad, desde el momento del inicio. Una contravención que tiene de uno a cuatro días de trabajo de actividad pública, tiene como sanción 
10 horas de detención para establecer su identidad. Y esto se repite cada vez que lo toman, no es que le pasó y...en eso hay impacto muy fuerte de los inmigrantes. (Fiscal, 22 años en el sistema judicial.)

Los senegaleses nosotros lo que vemos, no tanto en delitos sino en contravenciones: el uso indebido del espacio público para la venta. Por ejemplo, no sé si lo podés llegar a ver en lo que es, nosotros tenemos una zona conflictiva acá que es Once y Constitución nosotros estamos de turno con esa zona. Y lo que hacen es venta de anillos, de bijouterie. Y lo que termina, porque ellos no entienden como es el procedimiento, y muchas veces nos pasa que, nosotros por lo que dice la ley Contravencional, el procedimiento Contravencional digamos, tenemos que secuestrar elementos, lo que están vendiendo. Y cuando la policía los secuestra ellos empiezan a resistirse y quedan detenidos por resistencia o por atentado a la autoridad y tienen un problema más grande. Por no entender las leyes lamentablemente. Porque después capaz que vienen y piden la devolución y nosotros lo devolvemos. O si se pasa, si nosotros entendemos que no es una contravención sino una falta se lo devuelven pero... el problema es ese ¿no? ellos no entienden la ley y pasa. Delitos mucho nosotros lo que vemos, lo que nos surge estadísticamente del año pasado: no, senegaleses no tenemos muchos delitos. Solamente en relación a esta contravención. Exactamente. Contravención que lo que nosotros decimos acá, que es el artículo 83 que es el de utilizar el espacio público con fines de lucro indebidamente. Más bien si no tengo autorización, y me pongo un mantel o lo que sea. (Prosecretaria 20 años en el sistema judicial)

De la misma manera, otro de los motivos por los que se aplicaría la pena de detención sería la resistencia a la autoridad. Esta cuestión podría aplicarse también a los nativos, sin embargo, en el caso de los migrantes se hace referencia a la incapacidad de los mismos para "entender la ley" que, consecuentemente, provocarían esta doble penalidad.

Lo cierto es que, a partir de determinado código, el derecho clasifica y califica ciertas conductas como más o menos graves, en términos de Marx, (2008:40):

Depende en cierta medida de la sociedad oficial el catalogar determinadas violaciones de sus reglas como crímenes y otras como meras faltas. Esta diferencia de nomenclatura, lejos de ser indiferente, decide el destino de miles de hombres, y el tono moral de la sociedad.

Como manifiestan los entrevistados, los artículos 83 y 84 del Código Contravencional no permiten la venta callejera. En este sentido, es que se entiende que las leyes tienen efecto de verdad, no hay lugar para el cuestionamiento de lo que dictamina porque "el derecho es, sin duda, la forma por excelencia del poder simbólico de nominación que crea las cosas nombradas y, en particular, los grupos sociales" (Bourdieu, 2000:198) El poder propio de la ley se aplica para definir cuáles serán las desviaciones a las normas que se perseguirán mayormente, no sin cierto sesgo 
arbitrario y, por lo tanto, sobre qué sectores sociales se ejercerá el control desde el estado. Una cita de Foucault (2002: 277-278) permite clarificar este punto:

La penalidad sería una manera de administrar los ilegalismos, de trazar límites de tolerancia, de dar cierto campo de libertad a algunos, y hacer presión sobre otros, de excluir a una parte y hacer útil a otra; de neutralizar a éstos, de sacar provecho de aquéllos. En suma, la penalidad, no reprimiría pura y simplemente los ilegalismos; los diferenciaría, aseguraría su economía general. Y si se puede hablar de una justicia de clase no es sólo porque la ley misma o la manera de aplicarla sirvan a los intereses de clase, es porque toda la gestión diferencial de los ilegalismos por la mediación de la penalidad forma parte de esos mecanismos de dominación.

De este modo, el sistema judicial se consolida como una institución del aparato estatal que garantiza la reproducción de las relaciones de clase, ejerciendo el control social sobre determinadas poblaciones, fijándolas en "sus lugares" y perpetuando así estados de desigualdad.

La ley invisibiliza las relaciones de poder que el uso y apropiación del espacio público implica, al presentar la norma como el producto de un trato entre sujetos libres que deciden convivir bajo la misma. Resulta lógico que todo aquel que se desvíe de esa norma sea identificado, señalado y penado. De este modo, la aplicación de la ley, "que es igual para todos", sobre individuos en un conflicto individual, encubre las relaciones sociales de dominación y poder subyacentes.

Asimismo, el sistema judicial -en su calidad de ente estatal- encubre, al desplegar su aspecto represivo, el proceso de exclusión previo por el que atraviesa el migrante- la imposibilidad de acceder a un trabajo formal, en tanto derecho humano- completándose, con la sanción que la pena implica, el círculo en el que se encadenan propiedad privada-estado y derecho- que Marx (2008:43-44) describiera del siguiente modo:

La vida material de los individuos, que en modo alguno depende de su simple voluntad, su modo de producción y la forma de intercambio, que se condicionan mutuamente, constituyen la base real del Estado y se mantienen como tales en todas la fases en que siguen siendo necesarias la división del trabajo y la propiedad privada, con absoluta independencia de la voluntad de los individuos. Y estas relaciones reales, lejos de ser creadas por el poder del Estado, son, por el contrario, el poder que crea al Estado. Los individuos que dominan bajo estas relaciones tienen (...) que dar necesariamente a su voluntad, condicionada por dichas determinadas relaciones, una expresión general como voluntad del Estado, como ley, expresión que está dado siempre por las relaciones de esta clase, como con la mayor claridad demuestran el derecho privado y el derecho penal. 
Desde la perspectiva de la ley y sus representantes, el espacio público no debería ser ocupado por aquellos que han sido "incapaces" de insertarse en el mercado laboral formal. Es decir, el espacio público no debería ser desordenado por este tipo de actividades desarrolladas por aquellos individuos que no han logrado obtener por los canales "normales", un empleo. Por otra parte, este tipo de actividad atenta contra el derecho de los "propietarios" y de quienes "pagan sus impuestos". En ambos aspectos negativos de este tipo de actividades se interpela a un sujeto responsable de su propia situación de exclusión.

En fin, los sectores que ven en el espacio público un lugar donde suplir la negación al derecho a un trabajo formal son señalados como desviados. Ya que, en este caso, el uso del espacio público se encuentra atravesado por el de la propiedad privada y la venta callejera remite a la violación de dicha propiedad. Es allí cuando el Estado, por medio del poder judicial, coloca los límites de lo legal y lo no legal. Es allí donde el derecho prescribe lo desviado no solo establecido en el derecho sino también supone un juicio moral acerca de lo normal. Sobre este aspecto vinculado a la moralidad se tratará el siguiente apartado.

\section{DISTANCIAS Y FRONTERAS MORALES ENTRE NATIVOS Y MIGRANTES EN EL USO DEL ESPACIO PÚBLICO}

Si consideramos que "no solo hacemos la experiencia física de la ciudad, no solo la recorremos (...) sino que imaginamos mientras viajamos, construimos suposiciones sobre lo que vemos, sobre quienes se nos cruzan, las zonas de la ciudad que desconocemos y tenemos que atravesar para llegar a otro destino, en suma, que nos pasa con los otros en la ciudad. Gran parte de lo que nos pasa es imaginario, porque no surge de una interacción real" (García Canclini, 1999:89), muchos de los relatos sobre el uso del espacio público por parte de los migrantes se elaborarán a partir de interacciones reales pero también por "espacios imaginados". Esas representaciones refuerzan las fronteras materiales y simbólicas entre nativos y migrantes, así como los lugares subordinados y de poder de cada uno de ellos:

Debido al hecho de que el espacio social está inscripto a la vez en las estructuras espaciales y las estructuras mentales, que son en parte el producto de la incorporación de las primeras, el espacio es uno de los lugares donde se afirma y ejerce el poder, y sin duda en la forma más sutil, la de la violencia simbólica como violencia inadvertida... (Bourdieu, 1993:120)

En la construcción imaginaria de la ciudad, sus zonas y personajes, los extranjeros pueden ser vistos comerciando en la vía pública. Ello supone su presencia física y prolongada en el tiempo. Contrariamente, el espacio público, suele estar concebido en las ciudades actuales como un lugar de tránsito, donde pueden efectuarse contactos e interrelaciones momentáneas pero no 
actividades, como las del comercio callejero, que implican permanencia al menos por cierta cantidad de horas al día.

En este sentido, es que la venta callejera, además de ser una actividad señalada como desviada legalmente, supone además, desde un punto de vista moral, un uso ilegítimo de ese espacio ya que se convierte en un lugar donde esos sectores sociales "resuelven" necesidades que, desde la perspectiva de los sectores integrados, deberían tener "soluciones privadas". Particularmente, en relación a los migrantes, los entrevistados atribuyen esa cuestión a "valores culturales" o "características idiosincráticas" propias de las colectividades en cuestión.

Paraguayos nosotros no. Tenemos lo que podría llegar a ser de, también el uso de espacios públicos, de la contravención, pero en lo que es la venta de comida: lo que es chipá, lo que ellos dicen sopa paraguaya. También en la zona de Once tenemos mucho eso, y en la zona de Constitución también, en lo que es la estación de trenes. (Prosecretario, 5 años en el sistema judicial.)

Si. Los senegaleses son los que están realizando venta ambulante. Por eso digo, la venta ambulante es una de las contravenciones en la que uno ve mayor cantidad de personas extranjeras." (Secretaria, 12 años en el sistema judicial.)

Lo que sí creo que pasa es que en el caso de la ciudad es que los grupos migratorios, especialmente los países como Bolivia y Paraguay, donde existe una cultura más del emprendedorismo y de la autogestión...se encuentran con este problema de que vender en la vía pública es una contravención. Y eso sí, es la realidad, uno va a Bolivia o esos países donde un microemprendimiento es un modo de subsistencia, eh... y cuando vienen acá a la ciudad y empiezan a trabajar...que es muy habitual... no sé si podría decir que la mayoría, pero me animo a decir que la mayoría de los micro microemprendedores que hay por la ciudad son de comunidades de Bolivia, de Paraguay. Entonces en cuanto a nuestro problema es que bueno...lo encuentran de una manera un poco más burocrático que en sus países de origen. Quizás no están esas reglas en juego. Lo único que se me ocurre es esto de las contravenciones, que tiene que ver más con el impacto cultural que genera una migración acá, donde culturalmente... sostienen $\mathrm{o}$ generan ingresos con microemprendimientos o actividades pequeñas y cuando vienen acá se encuentran con que bueno... tienen que buscar una autodecisión y que no pueden vender en la calle...si vos caminás por cualquier núcleo urbano en Bolivia, te encontrás con emprendedores en todas partes. Esto no pasa mucho acá, entonces me imagino que ahí sí... es poco feliz decir que el grupo, supongamos de bolivianos que, buscando subsistir, desarrolla un emprendimiento y vende en la calle vende con la vocación de cometer la contravención. Sería no entender el problema, y creo que es justamente el impacto cultural que genera un grupo migratorio en otro país que tiene sus reglas, 
que responden a otro tipo...a otra realidad. (Escribiente, dos años en el sistema judicial)

De esta manera, en el caso de los migrantes, se incorpora a las explicaciones, la cuestión "cultural". Se asimila que en sus países de origen "este tipo de actividades es común", por tanto, se traduce una situación socioeconómica desfavorable de los extranjeros a una práctica cultural.

Contravenciones tenemos peruanos en la venta en la vía pública y...digamos peruanos en la venta en la vía pública, pero cuando uno recorre Perú o recorre...esto es una forma habitual de comercio allá, de hecho si usted va a dos cuadras de acá que esta el consulado de Perú, va a ver que cerca de ahí están lo que ellos llaman los jaladores, que son gente que en la vía pública capta clientes para llevarlo al negocio donde se saca la foto o se hace una fotocopia para los documentos, es decir es muy común que cualquier comerciante que quiera incrementar, aun establecido en un local, que quiera incrementar su consumo, busque jaladores que son gente que dice "fotocopias", "fotografías", a tanto el precio, y usted lo ve arbolitos exactamente, nosotros lo vemos con el cambio, no es cierto? Por supuesto que allá también hay arbolitos para el cambio. Entonces es muy común, aun para el transporte público. Viene uno que se baja y dice "a tal lugar, a tal lugar, vamos rápido"...es decir, son especies de voceros de la actividad comercial, entonces para ellos está bastante incorporado esto de la vía pública, realmente se sorprenden de que eso estuviese tan prohibido o fuera tan molesto o los comerciantes establecidos se quejen. (Fiscal, 22 años en el sistema judicial.)

Sancionar este tipo de uso del espacio público manifiesta renovadamente la relación desigual de poder y dominación entre migrantes y el sistema judicial. En esa sanción se afecta el derecho al trabajo del migrante.

Frente este escenario, el espacio público resulta un lugar hostil para los migrantes, ya que, sus prácticas son valoradas negativamente y perseguidas con el beneplácito legal. Al respecto, Taylor, Walton y Young (2007:145) sostienen que "una sociedad que no puede o que no quiere proporcionar a su población una cantidad suficiente de empleos o espacio donde vivir es una sociedad que necesita tomar como víctimas propiciatorias y rotular a una cantidad cada vez mayor y más variada de individuos." Es decir, en este caso, a mayor negación de acceso a derechos mayor también el proceso de estigmatización y señalamiento de los migrantes así como sus actividades "desviadas".

El estigma de seres excluidos que <<escogen>> dedicarse a este tipo de actividades ensombrece la identidad de determinados grupos de migrantes y erige fronteras "morales" entre los nativos y los extranjeros. En este sentido, la venta callejera es asociada con el desorden y la suciedad, generando una suerte de "inseguridad sanitaria" (Cosacov y Perelman, 2011: 311). Es así 
que se considera a los migrantes como sujetos poco higiénicos, que no respetan normas de sanidad y que mayormente están satisfechos con dedicarse a este tipo de actividades laborales:

En la zona de Liniers, por ejemplo, la mayoría de los bolivianos arma todo este tema de la venta en la calle como que es de ellos, entonces es como que por ahí podes asociar como que es de ellos, por ejemplo, la venta de comida, es comida de ellos, porque es comida nacional de ellos, la hacen en la calle, ensucian todo, es un desastre, entonces imagino que si eso está totalmente adjudicado a un sector de inmigrantes (...) en Liniers hay como un mini barrio de Bolivianos y ahí se acrecentó bastante eso lo veo, todos los días que paso por ahí, y ahí si aumentó bastante, influyó. En realidad yo vivo en Ramos Mejía. $\mathrm{Si}$, si, impacto en el sentido de que aumento al cantidad de delitos, o sea, en este sector que yo veo, por ejemplo en esta zona es terrible la cantidad de delitos que hay todo el tiempo, todo el tiempo, desde la venta ambulante en la calle desde robos, que son así menores de saqueos en la calle a las personas, o sea caminar por Liniers es un desastre y creo que hay otras zonas en capital donde también influyó por ejemplo, hay cuida coches que son inmigrantes, creo que se acrecentó el delito, de hecho yo trabajaba en una fiscalía hace algunos años y venía mucha gente que era extranjera como imputados, no, entonces influyó, no eran sólo argentinos, había un porcentaje alto de extranjeros que estaban imputados por delito y contravenciones. (Secretaria, 5 años en el sistema judicial)

$\mathrm{Si}$, si delitos o contravenciones sí. Hay ciertos rubros en los que comúnmente encontrás inmigrantes porque generalmente siempre son trabajo que son en negro que son como trabajos de paso y ellos pueden acceder más fácil a eso y la persona que los contrata también los tiene más a la mano digamos, que son no se desde la famosa mafia de las flores, las que están...hay un grupo muy importante que me acuerdo que esta manejado por peruanos, tal vez sea casualidad, pero acaparaban ese rubro, que uno dice la mafia de las flores, bueno si, pero hacían mucha plata y era muy difícil dar con ellos porque no se, se ve que tenían un proveedor importante de flores pero ellos, ellos acaparaban ese rubro, ese como la venta ambulante, que en realidad la persona que vende no no pertenece a ninguna mafia sino que es un laburante pero los manejan, eso es una contravención, está penado, uno no puede vender lo que quiere en la calle porque tiene que pasar por ciertos controles bromatológicos y estos, esta clase de vendedores no pasan esos controles, la venta ambulante. (Oficial, 4 años en el sistema judicial.)

De esta manera, la venta de comida y otros artículos son asociados a conductas y sujetos desviados del correcto uso del espacio público. Se lleva adelante un proceso de etiquetamiento negativo de actividades que se desarrollan en las calles de la ciudad, estigmatizando a los migrantes que las desempeñan. Al decir de Cohen, (2012: s/p) 
Todo individuo o colectivo desviado integra una red de relaciones sociales en las que mantiene un vínculo asimétrico con quien define su lugar. La etiqueta que lo posiciona es la expresión visible de una representación que lo caracteriza. La etiqueta es la foto, es la imagen congelada, atemporal, que lo resignifica. Sin embargo, hay un proceso que produjo esta etiqueta y que lo ubicó y definió como desviado.

En este proceso de constitución de la otredad migrante, en relación a su uso del espacio público, los miembros del sistema judicial ocupan la posición dominante, producen y reproducen de modo más o menos evidente la posición de vulnerabilidad del extranjero. Evidenciar el proceso, desnaturalizarlo e interpretarlo teniendo en cuenta la relación de dominación que implica permite comenzar a desentrañar el rol de las instancias de control estatal del espacio urbano en los procesos de exclusión de los migrantes que comercian en la calle.

En este sentido, el sistema judicial, aun a nivel contravencional desempeña un rol central al ejercer la administración del uso del espacio público, obstaculizando y sancionando ciertas prácticas ejercidas por determinados sujetos o grupos de sujetos. Foucault (2004:175) lo describe del siguiente modo:

El poder disciplinario, en efecto, es un poder que, en lugar de sacar y de retirar, tiene como función principal la de enderezar conductas. (...) es un poder modesto, suspicaz, que funciona según el modelo de una economía calculada pero permanente. Humildes modalidades, procedimientos menores. (...). El aparato judicial no escapará de esta invasión apenas secreta. El éxito del poder disciplinario se debe sin duda al uso de instrumentos simples: la inspección jerárquica, la sanción normalizadora y su combinación en un procedimiento que le es específico: el examen.

Ahora bien, De Giorgi (2005), sostiene que actualmente se desarrollan novedosas formas de entender el crimen y, por ende, de diseñar la política criminal. Algunos de los elementos, que este autor señala como nuevos, merecen su mención ya que también se hacen presentes en las entrevistas. Aun sin poder definirla como una nueva perspectiva criminológica, De Giorgi, hipotetiza que tras la "crisis del modelo terapéutico y tratamental" que se produce junto con la de los estados de bienestar, se inaugura un momento de escepticismo criminológico basado en la pérdida de creencia tanto de los objetivos (resocialización, reeducación del criminal) como de los instrumentos (cárcel) del modelo disciplinar y que será ocupado por una política que ya no busca con la sanción, corregir sino intimidar, que procura ser eficiente (inversión de menores recursos y obtener mejores resultados). Asimismo, la pena al perder su utilidad anterior se fundamenta tan solo en que el infractor la merece. El control se convierte en un fin en sí mismo, y se traduce en la mercantilización de la seguridad, en la intervención del comportamiento de no ya sujetos peligrosos sino clases o grupos de sujetos peligrosos, en zonas consideradas peligrosas, la vigilancia 
se dispersa, especialmente en el espacio urbano, en el que se edifican barreras, fronteras. (De Giorgi, 2005)

En esta nueva manera de concebir al delito y las posibles reacciones al mismo basadas en la identificación de "colectivos peligrosos", los migrantes internacionales se presentan fácilmente como posibles objetos de las mismas. Después de todo, son fácilmente identificables, marcables; muchos de ellos, se concentran en determinados espacios físicos en el que puede aplicarse la máxima del nuevo modelo descripto por De Giorgi (2005), es decir, la intervención sobre el ambiente, considerado como la única manera de prevenir la criminalidad callejera. En suma, los migrantes son un "otro" al que es posible señalar y al que puede adjudicársele eventuales riesgos y, por ende, justificar su control y vigilancia.

Lo cierto es que tanto lo señalado por Foucault como por De Giorgi se evidencia en el tratamiento que el sistema judicial despliega en relación a los migrantes que comercializan en la vía publica, en tanto como sujetos "desviados": afán de corregir e intimidar se aúnan en la administración de la justicia y en la aplicación de las penas.

En suma, cotidianamente, se crean y recrean fronteras entre sujetos, ligadas a distancias y proximidades sociales y morales. Moralidades de los espacios pero también de las personas. A los conflictos, que implican la definición de cuál es el uso legítimo y cual el ilegítimo del espacio público, se suma, cuando se trata de migrantes, las representaciones que los identifican como un elemento foráneo que, por lo tanto, poco o nada tienen derecho a decir frente a lo que la ley y quienes la administran establecen. De modo que, si el migrante es pensado por los entrevistados como un elemento exógeno, resulta razonable que se aplique una sanción. Es más, adquiere mayor legitimidad que si se tratara de un nativo, ya que si el migrante no ha formado parte de nuestra comunidad nacional "desde siempre", lo menos que puede exigírsele es probar su compromiso con "nosotros" y con "nuestras" normas aun cuando no sean las suyas o no las haya fundado.

En el imaginario social que se construye sobre el migrante- latinoamericano fundamentalmente ${ }^{11}$ - y su presencia en el espacio público se entrelazan representaciones sobre diversas maneras de desviarse de un uso "ordenado" y "legal" del mismo, creando así un espacio imaginario caracterizado por el peligro y la amenaza que acecharía a los nativos.

La verdad que no, creo que en parte tiene que ver con sus costumbres o sea por ejemplo la forma de vida que llevan los bolivianos en Liniers creo que es parte de sus costumbres de

\footnotetext{
11 Como se hace evidente en las entrevistas, este imaginario también se encuentra en relación a los migrantes africanos, fundamentalmente senegaleses.
} 
vender en la calle sus comidas típicas, o sea creo que ellos están acostumbrados a eso, pero acá nosotros tenemos una reglamentación que no lo permite, pero bueno ahora sí parece que lo permite, pero imagino que parte tiene que ver con sus costumbres otra parte tiene que ver con que acá no hay exigencias no hay una reglamentación firme, entonces eso yo creo que son cosas que como libertinaje y entonces bueno hacen lo que quieren y es como una ola que lleva a la otra y se va haciendo más grande acá no, acá creo que lo que falta con la inmigración es una reglamentación fuerte, por ejemplo vos para entrar a Estados Unidos tenés que tener de todo, y vimos el caso reciente, mentís, vas presa, las chicas estas que mintieron en su declaración jurada van presas acá eso no pasa ni locos, entonces acá entra cualquiera como pancho por su casa y hacen lo que quieren, hacen lo que quieren, acá vos tenés un puesto al lado del otro en la calle, todos vendiendo donde la gente quiere bajar por la calle para poder caminar por ahí y con miedo, porque yo a veces camino por ahí y no sabes quién te va a robar, si te sacan la cartera si esto si lo otro, y tenés la comisaría a la vuelta y ahí en General Paz y Rivadavia tenés un puesto policial y nadie hace nada, nadie hace nada, tiene que haber un gran operativo algo realmente grave para hacer algo. (Secretaria, 5 años en el sistema judicial.)

Tiene que ver más con cuestiones culturales. No es un delito, pero -no sé- se vive denunciando a la comunidad boliviana en la zona de Liniers porque tienen otro tipo de costumbres de, de alimentación, de fiestas populares y de lo que sea. Y tienen otro cuidado y otra manera de llevarse con lo público, que hay un choque cultural muy importante, sucios, que ensucian bienes públicos; que tiran deshechos en la vía pública; cortan calles; los domingos son difíciles -en Liniers- que se suelen divertir bastante y dejan todo un poquito desordenado. Pero no, tampoco es para calificarlo como una cuestión delictual grave, son contravenciones. Básicamente son contravenciones o faltas, que es todavía menos, es algo administrativo, igual que una multa, digamos". (Secretario, Director Oficina de atención a víctimas, 12 años en el sistema judicial)

En este sentido, la alteridad vulnera la sensación tranquilizadora del "estar entre nosotros", de allí la búsqueda de garantizar cierta uniformidad y similitud que permita el establecimiento de un espacio libre de sorpresas, ambivalencias y conflictos. En cambio, el migrante es portador de la imprevisibilidad al tiempo que "... se niega a permanecer confinado en un "lugar lejano" o abandonar nuestro terruño y, por esto, desafía a priori la simple estrategia de separación espacial y temporal..." (Bauman, 1998:100). Además, cuando desarrolla ciertas actividades en el espacio público-como comerciar- es construido como desviado a partir de la aplicación de la norma y su sanción. La criminalización de la venta callejera supone entonces el despliegue de una serie de dispositivos, instituciones, funcionarios, en fin, activa un engranaje cuya consecuencia es ubicar al migrante en una posición de vulnerabilidad. Asimismo, origina categorías de percepción, prejuicios, 
miedos, preocupaciones, en suma, representaciones negativas acerca de los extranjeros erigiendo fronteras materiales y simbólicas entre nativo y migrantes. La presencia de estos últimos se torna en algún sentido moralmente insoportable, después de todo "nada es más intolerable que la proximidad física (vivida como promiscuidad) de personas socialmente distantes." (Bourdieu, 1993:123).

\section{REFLEXIONES FINALES}

La imprevisibilidad que porta el migrante se refleja en las manifestaciones de los entrevistados respecto a la necesidad de controlar, disciplinar y regular el modo en que se apropian del espacio público, en este caso, en relación a la venta callejera. Desde la perspectiva de los representantes de la ley, estos extranjeros forman parte, de aquellos sujetos que no han escogido insertarse formalmente al mercado laboral, ya sean por imposibilidades individuales, preferencias culturales o de idiosincrasia, se trata de sujetos que transgreden la norma, consecuentemente, deben ser penados. Específicamente, en su dimensión legal, el sistema judicial asume la función de la punición de determinadas prácticas que constituyen un ataque al derecho de la propiedad. Se ocupa de los migrantes en tanto potenciales infractores de normativas instituidas para proteger la propiedad, como es alegado por los entrevistados respecto a la venta callejera. No obstante, esta actividad refiere también a la violación de las normas sobre el uso debido del espacio público.

Lefebvre (1974:223) sostiene que “...es el espacio y por el espacio donde se produce la reproducción de las relaciones de producción capitalista. El espacio deviene cada vez más un espacio instrumental." El uso del espacio público como recurso se materializa ejemplarmente en el caso de la venta callejera a la que se dedicarían determinados migrantes (sobre todo de origen boliviano, paraguayo, peruano y africano).

Desde una perspectiva de derechos humanos, el derecho al trabajo y a la subsistencia debiera ser prioritario, sin embargo, la interpretación desde una postura punitiva conduce a que el sistema judicial refuerce y reproduzca el proceso de exclusión en el que se encuentran asidos ciertos miembros de las colectividades migrantes mencionadas. En términos de Wacquant (2009:67) "...la penalización de la precariedad crea nuevas realidades que permiten al propio sistema punitivo de la Ciudad de Buenos Aires seguir siendo necesario, útil, funcional.

Por último, puede afirmarse que el rol estatal de gestión de las migraciones, a partir de determinada política que intente regular el ingreso y permanencia de los extranjeros ${ }^{12}$ al interior

\footnotetext{
12 Sobre esta cuestión puede consultarse el interesante artículo: DOMENECH, E. (2011). Crónica de una "amenaza" anunciada. Inmigración e "ilegalidad":visiones de estado en la Argentina contemporánea. En L.
} 
de las fronteras nacionales encuentra ese mismo afán de control a nivel micro, cuando se trata de administrar la existencia del día a día de los migrantes que, en este caso, desarrollan la actividad del comercio en la vía pública. En fin, en la tarea ambiciosa de "gobernar" la problemática migratoria, a nivel nacional como municipal, el Estado ejerce su poder de policía resultando en un proceso cuya culminación es la constitución de la otredad migrante como desviada, reforzando así la posición de desigualdad y exclusión de parte de los miembros de las colectividades extrajeras residentes en "nuestra" comunidad nacional.

\section{REFERENCIAS BIBLIOGRÁFICAS}

BAUMAN, Z. (1999). La globalización. Consecuencias humanas. Brasil: FCE. Trabajo, consumismo y nuevos pobres. Barcelona: Gedisa.

BECKER, H. (2010). Outsiders. Buenos Aires: Siglo XXI.

BENENCIA, R. (2003). Apéndice. La inmigración limítrofe. En F. DEVOTO, Historia de la inmigración de la Argentina (págs. 433-484). Buenos Aires: Sudamericana.

BOURDIEU, P. (1993). La miseria del mundo. Argentina: FCE. (2000). La dominación masculina. Barcelona: Anagrama.

CARRIÓN MENA, F. (2004). SELECTED WORKS. Recuperado el 14 de Abril de 2013, de http://works.bepress.com/cgi/viewcontent.cgi?article=1109\&context=fernando_carrion

COHEN, N. (2012). Profetizando al diferente. Revista Controversias y Concurrencias Latinoamericanas, ALAS. (6), 187-203.

COSACOV, N., \& PERELMAN, M. (2011). Modos de apropiación de la ciudad, conflicto y gestión del espacio urbano. La construcción de fronteras en la ciudad de Buenos Aires. En DI VIRGILIO, HERZER MERLINSKY \& RODRIGUEZ, La cuestión urbana interrogada. Transformaciones urbanas, ambientales y políticas públicas en Argentina. (págs. 291-318). Buenos Aires: Café de las Ciudades.

COURTIS, C. (2006). Hacia la derogación de la Ley Videla: la migracion como tema de labor parlamentaria en la Argentina de la década de 1990. En GRIMSON, A. y JELIN, E. Migraciones regionales hacia la Argentina: diferencia, desigualdad y derechos. Buenos Aires : Prometeo.

DE GIORGI, A. (2005). Tolerancia Cero: estratégias y prácticas de la sociedad de control. Roma, Italia: Virus Editorial.

DEVOTO, F. (2003). Historia de la inmigración en la Argentina. Buenos Aires: Sudamericana.

DOMENECH, E. (2011). Crónica de una "amenaza" anunciada. Inmigración e "ilegalidad": visiones de estado en la Argentina contemporánea. En L. Feldman-Bianco, C. Rivera Sánchez, \& M. Villa

Feldman-Bianco, C. Rivera Sánchez, \& M. Villa Martínez, La construcción social del sujeto migramte en América Latina: prácticas, representaciones y categorías (págs. 31-77). Quito: CLACSO. 
Martínez, La construcción scial del sujeto migrante en América Latina: prácticas, representaciones y categorías (págs. 31-77). Quito: CLACSO.

FOUCAULT, M. (2002). Vigilar y castigar: nacimiento de la prisión . Buenos Aires: Siglo XXI editores.

GARCÍA CANCLINI, N. (1999). Imaginarios urbanos. Buenos Aires: Eudeba. (2006). Diferentes, desiguales y desconectados. Barcelona: Ed. Gedisa.

INDEC. (2004). Aquí se cuenta. Revista informativa del Censo 2001.

(febrero de 2012). Instituto Nacional de Estadística y Censos. Obtenido de

http://www.censo2010.indec.gov.ar/cuadrosDefinitivos/analisis_censo_feb12.pdf

JODELET, D. (1986). La representación social: fenómenos, concepto y teoría. En MOSCOVICl, Psicología social (págs. 469-494). Barcelona: Paidós.

(1991). Representaciones sociales, un area de expansión. En PAEZ, SAN JUAN, ROMO, \& VERGARA, SIDA: imagen y prevención. Madrid: Fundamentos.

LEFEBVRE, H. (1974). Espacio y política: el derecho a la ciudad. Barcelona: Península.

MARCOS, M., \& MERA, G. (2009-2010). Pobreza estructural y migración limítrofe: aportes para pensar su articulación espacial en la aglomeración Gran Buenos Aires. Estudios socioterritoriales. Revista de Geografía (8), 137-155.

MARX, K. (2008). Elogio del crimen. Madrid : Sequitur.

MURILLO, S. (2002). Sujetos a la incertidumbre : transformaciones sociales y construcción de subjetividad en la Buenos Aires actual. Buenos Aires: Centro Cultural de la Cooperación.

OSZLACK, O. (1991). Merecer la Ciudad: Los pobres y el derecho al espacio urbano. Buenos Aires: Cedes - Humanitas.

TAYLOR, I., WALTON, P., \& YOUNG, J. (2007). La nueva criminología. Contribución a una teoría social de la conducta desviada. Buenos Aires: Amorrortu.

TISCORNIA, S. (2004). Burocracias y violencia. Estudios de antropologia jurídica. Buenos Aires: Antropofagia.

TISCORNIA, SARRABAYROUSE, \& EILBAUM. (2004). De los edictos de policía al Código de Convivencia Urbana. Las trágicas paradojas de los procesos de construcción de espacios de convivencia. En TISCORNIA, S. Burocracias y violencia. Estudios de antropología jurídica. (págs. 89124). Buenos Aires: Antropofagia.

WACQUANT, L. (2007). Los condenados de la ciudad : gueto, periferias y Estado. Buenos Aires: Siglo XXI. Gedisa.

(2009). Castigar a los pobres. El gobierno neoliberal de la inseguridad social. Barcelona:

Trabalho enviado em 03 de maio de 2015.

Aceito em 28 de maio de 2015. 